\title{
Uma leitura tensiva do poema Romance Sonámbulo
}

A tensive reading of the poem Romance Sonámbulo

Alexandre Silveira CAMPOS (UNESP) alexandre.campos@unesp.br

Recebido em: 03 de abr. de 2020. Aceito em: 10 de maio de 2020.
CAMPOS, Alexandre Silveira. Uma leitura tensiva do poema Romance Sonámbulo. Entrepalavras, Fortaleza, V. 10, n. 2 , e1862, p. 1-16, maioago/2020. DOI: $10.22168 / 2237-6321-$ 21862.

Resumo: O título desse artigo faz referência direta, em tom de homenagem, a um texto seminal do semioticista Claude Zilberberg, publicado em 1972, na célebre coletânea de ensaios organizada por A. J. Greimas (Essais de Sémiotique Poétique). Portanto, este trabalho, seguindo a lógica do seu texto inspirador, pretende tocar na poesia, nesse caso, a partir do poema Romance Sonámbulo (1928), do espanhol Federico García Lorca, e na semiótica, a partir do ponto de vista tensivo, termo preferido por Zilberberg para descrever sua própria teoria, a atualmente também chamada semiótica zilberberguiana. Afastando-se gradativamente da estrutura narratológica e aproximando-se da articulação entre intensidade e extensidade, bem como de seus subprodutos, seguramente, o modelo tensivo tem muito a dizer de um acontecimento inesperado, como pretende-se ler aqui o poema de Lorca, o qual provoca não somente um, mas vários momentos de ruptura da lógica implicativa, erigindo uma verdadeira ode ao sentido da concessão.

Palavras-chave: Semiótica. Tensividade. Poesia. 
V. $10(2)$

1-16 maio-ago 2020

Abstract: The title of this paper makes a direct reference, as a tribute, to a fundamental text of the semiotician Claude Zilberberg, published in 1972, in the famous essay collection organized by A. J. Greimas (Essais de Sémiotique Poétique). So, this paper, following the logic of your inspiring text, intents to approach poetry from de poem Romance Sonámbulo (1928) by Spanish poet Federico García Lorca and, in the case of semiotics, from the tensive point of view, preferred term by Zilberberg to describe own theory, known as tensive semiotics. Moving away from the narrative structure gradually and approaching the articulation between intensivity and extensivity, as well as its by-products, surely the tensive model has a lot to say about an unexpected event, as we intend to interpret Lorca's poem, which causes not the only one but several moments of break of implicative logic, building a true ode towards the concession sense.

Keywords: Semiotic. Tensivity. Poetry.

\section{Introdução}

Este artigo tem o objetivo de levantar algumas questões sobre o ponto de vista da semiótica tensiva de Claude Zilberberg (1938 2018) aplicado a objetos literários, no caso específico, à poesia. Como ponto de partida, é preciso notarmos que a pergunta geral que está por trás dessa intenção é: Para que serve a gramática tensiva? (ZILBERBERG, 2009). Tal indagação já tem uma resposta dada pelo próprio Zilberberg, em artigo publicado com esse mesmo título, cuja pergunta ele atribui aos professores da USP Luis Tatit, Ivã Lopes e Waldir Beividas e que ele responde com uma síntese breve da teoria tensiva.

Para nós, essa resposta do autor da teoria tensiva aponta para dois sentidos. Um primeiro, de desafio para a tarefa de testar e ampliar as possíveis adoções analíticas do ponto de vista tensivo para sua aplicabilidade em variadas formas de linguagens, modos sincréticos de comunicação e até a outros campos do saber como a biologia ou física, por exemplo. E, em um segundo sentido, aponta para a tarefa de entender melhor quais são as bases da proposta e em quais fundamentos teóricos e pragmáticos ela se estabelece, já que, nas palavras de Zilberberg, a locução "para que serve? convida ao heroísmo ou ao ridículo se seu interlocutor não consegue convencer o desafiante em potencial" (ZILBERBERG, 2009, p. 104).

Aqui seguiremos o segundo sentido do desafio dado e tomaremos, como ancoragem, um artigo publicado por Zilberberg em 1972, na célebre coletânea organizada por A. J. Greimas, Ensaios de Semiótica Poética (GREIMAS, 1975), que, por diversos vieses, estabelecia elos entre a semiótica daquele momento e o texto poético. Nesse artigo, Zilberberg faz uma análise greimasiana do poema Bonne Pensée 
du Matin, de Rimbaud (2018). Não pretendemos fazer uma análise da análise, mas apenas pontuarmos como a preocupação com a poesia, mais precisamente com o poético e seus modos de engendramento estruturais, sempre fez parte das preocupações zilberberguianas. E ainda apontarmos que, mesmo sendo um exercício de leitura analítica, já aparecem ali traços daquilo que viria a ser um sólido passo adiante na epistemologia semiótica.

\section{0 objeto poético}

Toda escolha tem um grau de aleatoriedade que perpassa o pragmatismo, a coerência, a razão, mas, sobretudo, a afetividade. Assim, justificamos a escolha de um poema de Lorca como objeto para uma leitura tensiva, na mesma medida do objetivo que anteriormente nos propomos de, através de alguns recortes teóricos, apontarmos como Zilberberg afasta-se gradativamente da estrutura narratológica e aproxima-se da articulação entre intensidade e extensidade, bem como de seus subprodutos: a tonicidade e o andamento, relacionados ao campos do intenso, e a temporalidade e a espacialidade, relacionadas ao campo do extenso. E cada uma dessas categorias é mobilizada pelo seu maior ou menor grau de atuação, ou seja, a tonicidade pode variar entre mais tônica ou mais átona, o andamento entre mais rápido ou mais lento, a temporalidade entre mais breve ou mais longa e a espacialidade entre mais fechada ou mais aberta.

O poema Romance Sonámbulo (LORCA, 2003) foi publicado em 1928, no livro de poemas Romancero Gitano, que expressa, já no título, a dupla intenção de construção reelaborada: de um lado, uma determinada forma, o romance, e do outro, um conteúdo específico, a cultura cigana. Dentro desse conjunto maior de textos, este se relaciona com outros dois poemas do livro: o Romance de La Pena Negra e Muerto de Amor. Os três poemas, tanto pela estrutura quanto pelo conteúdo, formam uma espécie de trilogia simbólica do sonho, do amor e da morte.

Trataremos, nesteartigo, apenas do poema Romance Sonámbulo e, por uma opção didática de metodologia, passaremos à análise do poema começando pelo plano da expressão, sobretudo no que concerne ao agrupamento dos versos e aos seus modos de entrelaçamento.

Para melhor acompanhamento da análise, inserimos, a seguir, o poema completo. 


\section{10 (2)}

1-16

maio-ago 2020
Romance Sonámbulo

Verde que te quiero verde.

Verde viento. Verdes ramas.

El barco sobre la mar y el caballo en la montaña. Con la sombra en la cintura ella sueña en su baranda, verde carne, pelo verde, con ojos de fría plata.

Verde que te quiero verde. Bajo la luna gitana, las cosas la están mirando y ella no puede mirarlas. Verde que te quiero verde. Grandes estrellas de escarcha, vienen con el pez de sombra que abre el camino del alba. La higuera frota su viento con la lija de sus ramas, y el monte, gato garduño, eriza sus pitas agrias.

¿Pero quién vendrá? ¿Y por dónde? Ella sigue en su baranda, verde carne, pelo verde, soñando en la mar amarga.

-Compadre, quiero cambiar mi caballo por su casa, mi montura por su espejo, mi cuchillo por su manta. Compadre, vengo sangrando, desde los puertos de Cabra. -Si yo pudiera, mocito, este trato se cerraba. Pero yo ya no soy yo, ni mi casa es ya mi casa. -Compadre, quiero morir, decentemente en mi cama. De acero, si puede ser, con las sábanas de holanda. ¿No ves la herida que tengo desde el pecho a la garganta? -Trescientas rosas morenas lleva tu pechera blanca. Tu sangre rezuma y huele alrededor de tu faja. Pero yo ya no soy yo, ni mi casa es ya mi casa.

- Dejadme subir al menos hasta las altas barandas, ¡dejadme subir!, dejadme hasta las verdes barandas. Barandales de la luna

por donde retumba el agua.

Ya suben los dos compadres hacia las altas barandas.

Dejando un rastro de sangre.

Dejando un rastro de lágrimas.

Temblaban en los tejados

farolillos de hojalata.

Mil panderos de cristal

herían la madrugada.

Verde que te quiero verde, verde viento, verdes ramas.

Los dos compadres subieron.

El largo viento dejaba

en la boca un raro gusto

de hiel, de menta y de albahaca.

- ¡Compadre! ¿Dónde está, dime?

¿Dónde está tu niña amarga?

¡Cuántas veces te esperó!

¡Cuántas veces te esperara, cara fresca, negro pelo, en esta verde baranda!

Sobre el rostro del aljibe se mecía la gitana.

Verde carne, pelo verde, con ojos de fría plata.

Un carámbano de luna

la sostiene sobre el agua.

La noche se puso íntima

como una pequeña plaza.

Guardias civiles borrachos

en la puerta golpeaban.

Verde que te quiero verde, verde viento, verdes ramas.

El barco sobre la mar

Y el caballo en la montaña.

(LORCA, 2005, p. 127) 


\section{O plano da expressão}

O poema está dividido em cinco estrofes, onde cada uma expressa, na parte inicial do texto, possíveis estilos de discurso. Não abordaremos a complexa questão dos gêneros textuais. Como opção didática, assumiremos o conceito amplo de gênero dado incialmente pela 'Poética' (ARISTÓTELES, 1990) e, grosso modo, adotado na ampla tradição que percorreu a análise retórica até os pressupostos estruturalistas de análise do texto e do discurso. Tais macrocategorias, seja pela pertinência fulcral que essa divisão teve nos modos ocidentais de identificar a infinita tipologia textual, seja pela facilitação didática de tais termos, ainda hoje expressam a narrativa para o épico, a poesia para o lírico e o teatro para o dramático.

Como procedimento de análise, faremos a decomposição do poema em duas partes quanto ao uso desses discursos. Na primeira parte, tomaremos as três primeiras estrofes, observando que cada uma expressa, de forma independente e claramente definida, um estilo discursivo distinto.

A primeira estrofe, que começa com o hipnótico estribilho: Verde que te quiero verde, tem como predominante o tom do estilo lírico. Nesse caso, o eu aparece na pessoa verbal, mas se dilui. Esconde-se na medida em que segue, guiado pela isotopia forçosa do verde, a descrição da alvorada e da presença de uma mulher que espera em sua varanda. $\mathrm{O}$ feminino expresso por Ella é o centro da estrofe lírica, a varanda onde é observada e de onde ela também observa é o ponto de vista central em torno do qual os outros elementos, o barco, o cavalo, a sombra e a lua, giram: "Las cosas la están mirando/ y ella no puede mirarlas" (v. 11 e 12).

Próximo ao final da estrofe, antes de retomar o estribilho e encerrar o discurso lírico, há um verso que introduz uma interrogação e rompe com o tom assertivo: "¿Pero quién vendrá? ¿Y por donde?" (v. 21). Esse contraponto inicial, ainda dentro do lírico, tem também a função de introduzir e fazer uma espécie de ligação com a quebra significativa expressa na estrofe seguinte. Podemos já dizer que esse verso, sob a perspectiva do estilo tensivo da ascendência, está sob a categoria aspectual do restabelecimento e, portanto, envolve a direção fórica da aceleração, no caso, aceleração da ruptura (ZILBERBERG, 2011, p. 102). Os conceitos de "categoria aspectual" e "direção fórica", fundamentais na estrutura da teoria tensiva, serão tratados com melhor acuidade mais adiante, na análise. 
V. $10(2)$

1-16 maio-ago 2020

A segunda estrofe se constitui por um diálogo entre dois homens, um primeiro interlocutor que chega, talvez mais jovem, pois chamado de mocito, e um segundo interlocutor que chega à cena, chamado de compadre. Assim, a estrofe se caracteriza, no plano da expressão, pela forma do estilo do discurso dramático. Este caracterizado não apenas pela estrutura dialogal, mas também pela constituição do foco nos personagens em relação ao espaço, tanto por eles habitado quanto constituído, e pela modalização do tempo que passa a ser o tempo da relação entre eles.

As falas se intercalam entre os modos de pedido e resposta. As formas de interjeição do pronome de tratamento "- Compadre [...]" (v. 25, 29 e 35) e do verbo imperativo exclamativo "Déjadme [...]" (v. 47) que iniciam e perpassam as falas do primeiro interlocutor, aquele que chega (sangrando), contrastam com a passividade e a resignação do segundo interlocutor, aquele que está. Este, em um primeiro momento, resiste declarando sua condição de impotência, nos sublimes versos: "Pero yo ya soy yo/ Ni mi casa es ya mi casa" (v. 33 e 34). Em seguida, analisa e descreve seu interlocutor, em um sentido de reconhecimento e aproximação, para, depois, aquiescer ao pedido que lhe é dirigido e unir-se ao outro em um mesmo movimento de entrada e de subida, acolhimento e ascensão. Os últimos dois versos da segunda estrofe são descritivos e introduzem, assim, o terceiro estilo discursivo.

A terceira estrofe é de tom narrativo e possui apenas oito versos. Ela conta a passagem para o ambiente interno e descreve o movimento ascendente dos personagens em dois sentidos. No sentido que aponta para o que será alcançado, as altas varandas, ela se relaciona com o tempo futuro e, no sentido que aponta para o que se deixa, um rastro de lágrimas e sangue, se relaciona com o passado.

Dando prosseguimento à análise da forma do plano de expressão em relação aos estilos discursivos no que concerne ao agrupamento de versos, percebemos que, com a terceira estrofe, se encerra uma unidade do poema, que, para efeito de estudo, chamaremos de grupo de estrofes uniformes e que concerne à relação do plano de expressão com o plano do conteúdo. E, por conseguinte, com a quarta estrofe, inaugura-se uma segunda unidade, a qual chamaremos de grupo de estrofes variadas.

Essa quarta estrofe tem, nos dois primeiros versos e nos dois últimos, a predominância do estilo lírico, ou seja, retoma a estrutura do estribilho poético. Dos versos 63 ao 66 ( $3^{\circ}$ a $6^{\circ}$ verso da $4^{\mathrm{a}}$ estrofe), retoma a narrativa do percurso dos personagens que apareceram na 
estrofe anterior, indicando o movimento e o caminho percorrido. E dos versos 67 ao 70, reintroduz o diálogo entre as vozes que se iniciou na segunda estrofe. Assim, percebemos que essa quarta estrofe reúne os três estilos discursivos utilizados separadamente nas estrofes anteriores, porém não na mesma ordem, o que confirma a intenção de objeto desuniforme que se constrói.

Sigamos com a descrição do modo de estilo discursivo na estrofe final do poema, para passarmos aos possíveis significados do plano de expressão.

Na quinta e última estrofe, em acordo com o sistema variado iniciado na estrofe anterior, encontramos uma sequência mista de estilos discursivos. Em um esquema de alternância predominantemente binária, que gera uma espécie de ritmo estilístico, alternam entre si as formas de /narração/ e /lírica/. Os dois primeiros versos narrativos (v. 73 e 74) são seguidos de dois versos que retomam o estribilho cromático (v. 75 e 76). Na sequência, versos 77 a 80, a narrativa é retomada, agora como narrativa descritiva, e se encerra para novamente dar espaço ao discurso poético que finaliza o poema com a repetição idêntica da quadra que iniciou o texto.

Ainda notamos que há, no meio desse sistema de alternância, dois versos que se destacam por não se encaixarem bem em nenhum dos estilos que marcam o ritmo discursivo da estrofe. Alocados entre o encerramento narrativo e o encerramento poético, este que coincide com o encerramento do poema, os versos: "Guardias civiles borrachos/ en la puerta golpeaban" (v. 81 e 82) retomam a esfera do drama com a introdução, dessa vez, do som de golpes, o que estesicamente introduz o diálogo na estrofe anterior.

A pergunta que fazemos nesse ponto é: quais as grandezas que esse recorte da costura dos estilos discursivos faz aparecer ou, em termos zilberbergianos, faz vibrar no campo de presença? Nesse sentido, é importante delimitarmos que se trata ainda do plano da expressão e que, mesmo aqui, podemos inferir as categorias vibrantes, correlacionáveis aos modos de estruturação do poema.

No caso específico, visto até este momento, do encadeamento das estrofes que seguem três estilos diferentes de discurso, as relações entre as partes indicam uma relação dinâmica entre as categorias de / homogeneidade/, para as estrofes onde predomina apenas um modo de estilo discursivo, e de /heterogeneidade/, para as estrofes onde os estilos discursivos se intercalam. 
V. $10(2)$

1-16

maio-ago

2020

Para uma melhor visualização dos modos de estruturação dos estilos e das projeções de sentido das relações que eles mesmos estabelecem entre si no poema, optamos por um modelo de descrição visual utilizado pelo semioticista Jean Marie Floch, da década de oitenta, contido no célebre artigo onde ele analisa a propaganda dos cigarros News e onde foram dadas as bases para a aplicação de uma semiótica do visual e do conceito de semissimbolismo (FLOCH, 1987). Esse modelo tem a vantagem de visualização clara das relações entre as características estruturais do plano de expressão e os valores de projeção a elas relacionados. Ou seja, não trata apenas do plano da expressão, mas da sua relação com o plano do conteúdo e os valores de sentido daí decorrentes.

Assim, essa primeira análise do plano da expressão do texto de Lorca, que envolve a estrutura do encadeamento das estrofes de acordo com os modos de relação entre os estilos discursivos em que cada uma delas se constrói, poderia ser representada da seguinte maneira:

Gráfico 1 - Análise do Encadeamento de Estrofes

Poema

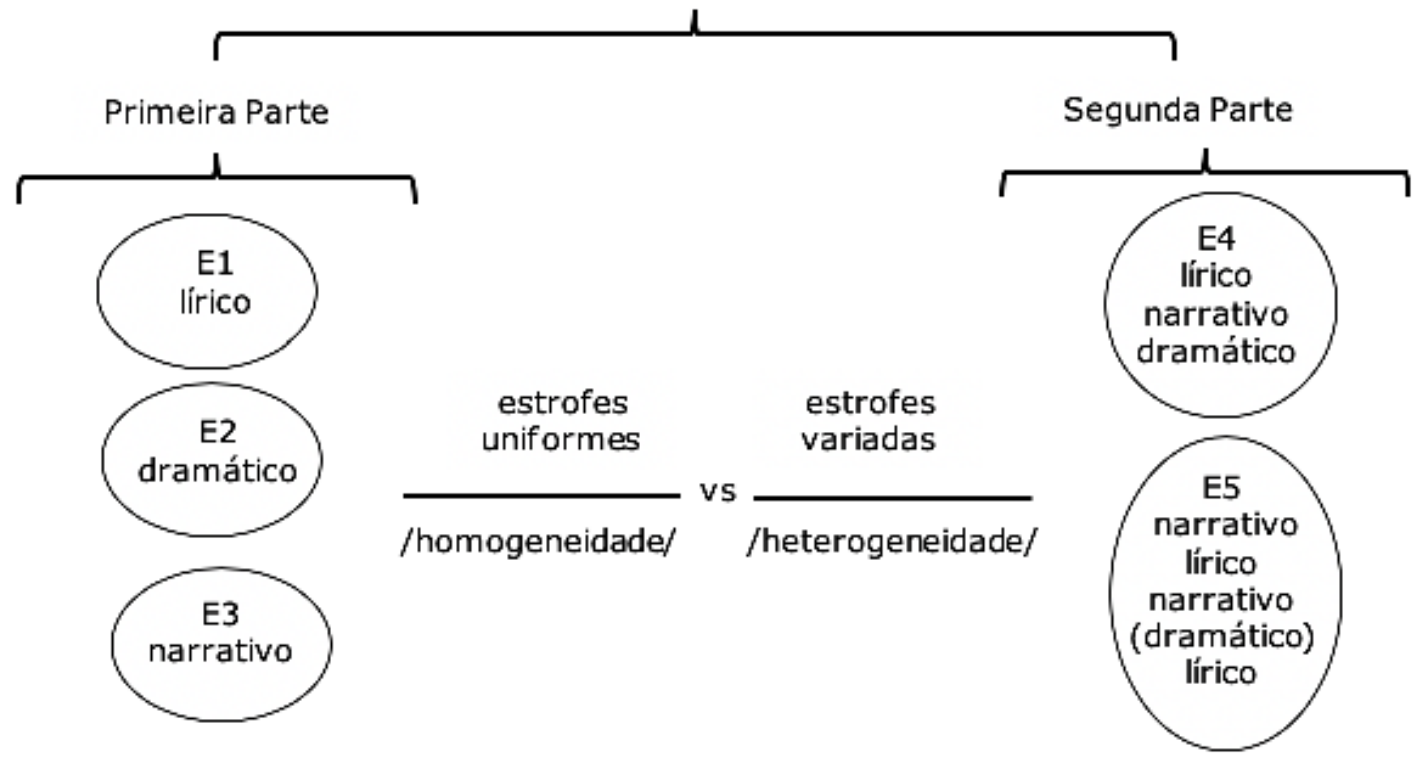

Fonte: autoria própria.

\section{Preceitos tensivos}

No entanto, até aqui, apenas descrevemos as relações que compõem o encadeamento das partes no plano da expressão e quais os 
valores que são projetados a partir dessas distinções de forma. Mesmo sobre essa pequena análise parcial, podemos aceitar o desafio de uma das primeiras premissas do ponto de vista tensivo: "a hipótese de que o discurso ao avançar procura, a partir dos mais e dos menos sugeridos e acumulados, reconhecer a direção crescente eleita" (ZILBERBERG, 2011, p. 64). Assim, a pergunta que fazemos agora é: em que medida a passagem da /homogeneidade/ para a /heterogeneidade/ está relacionada com os modos tonificação e atenuação, ou seja, com a subdimensão tonal, no plano da expressão? Ou dito de outra forma, em que medida as mudanças na organização dos estilos sugerem uma aceleração ou uma desaceleração e constroem, ainda nesse mesmo plano, as relações inversas ou conversas?

Colocadas essas questões sob o ponto de vista tensivo, segundo o qual "um sujeito que procede mediante misturas e triagens interligadas, ele se vê obrigado, queira ou não, ora a incluir excluídos, ora a excluir incluídos" (ZILBERBERG, 2011, p. 68), observamos que, no nosso objeto, a distribuição homogênea dos estilos, que constitui a característica da primeira parte do poema, colabora, de acordo com a valência da extensidade, para um sentido difuso, na medida em que se emprega um esforço de separar elementos que 'naturalmente' aparecem unidos e ordená-los em sequência. Assim, na nossa leitura, na metade inicial do poema, os estilos lírico, narrativo e dramático, pelo modo de colocação que opera por isolamento e pela triagem desses elementos, instituem a direção difusa em um primeiro momento.

Desse modo, na segunda parte do poema, onde as estrofes variadas operam pela mistura dos estilos a partir de uma distribuição heterogênea desses elementos, observamos que, por força da leitura linear do poema, ocorre a passagem do difuso para o concentrado. Ou seja, os elementos que resultaram de um esforço de exclusão mútua, encontram-se (forçosamente) todos incluídos em uma mesma unidade. Assim, a mistura de estilos na mesma estrofe e essa distribuição heterogênea de elementos provocam, ao contrário do que se poderia esperar, o efeito de concentração.

Para observarmos quais são as possíveis consequências desse arranjo que se dá no plano da expressão do texto, lançaremos mão da esquizia inaugural da teoria zilberbergiana onde a própria tensividade, tomada como valor primeiro, gera as valências de intensidade e extensidade, e estas, por sua vez, dividem-se em subdimensões que, de acordo com os modos de relação, podem gerar correlações conversas 
V. $10(2)$

1-16

maio-ago

2020

ou inversas e apontar quais são as grandezas que ocupam, ou que aparecem, no espaço tensivo.

Gráfico 02 - Esquizia Inaugural da Tensividade

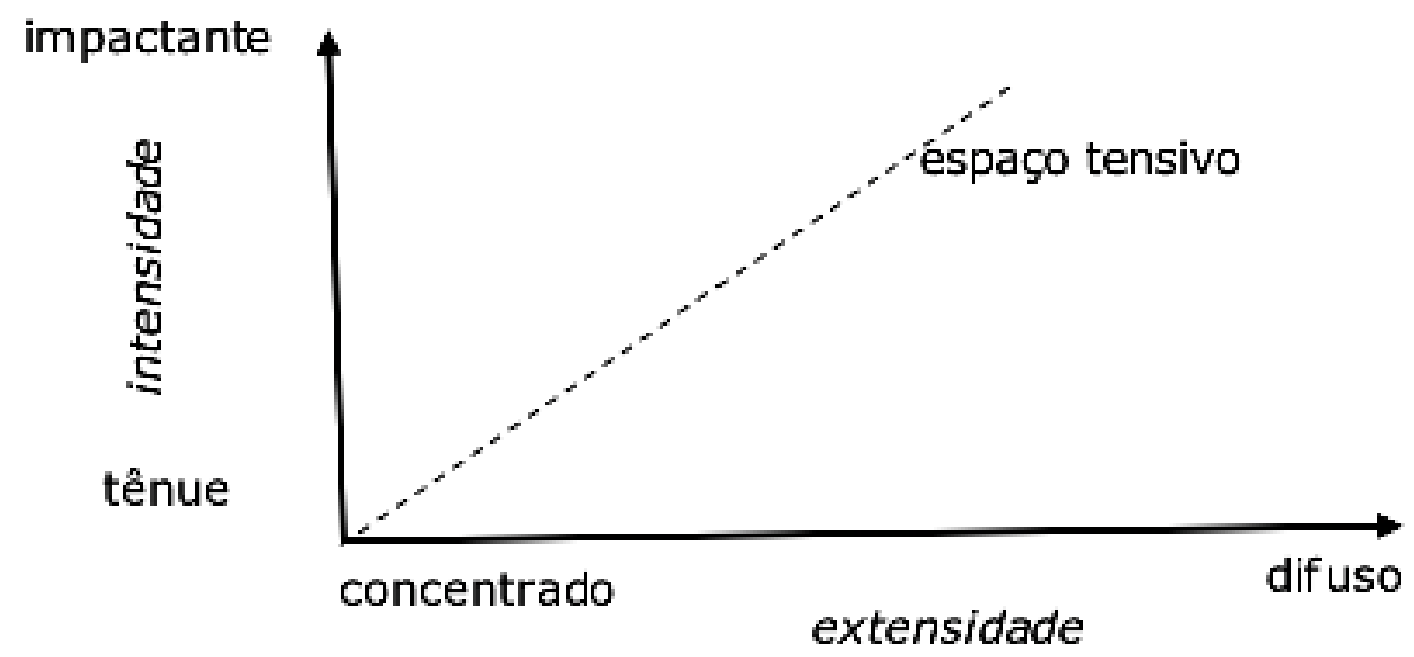

Fonte: Zilberberg (2011).

As dimensões de intensidade e extensidade ainda se dividem em subdimensões de andamento e tonicidade (para o intenso) e temporalidade e espacialidade (para o extenso). Estas, por sua vez, operam uma série de oposições, descritas na 'segunda analítica do sensível' (ZILBERBERG, 2011, p. 84), que podem ocorrer, de acordo com a sintaxe de cada discurso, por saltos ou gradações descritas na 'primeira analítica do sensível' (ZILBERBERG, 2011, p. 79).

Desenvolvendoalógica das possíveis relações entreas subdimensões, a semiótica tensiva, sob a égide das operações cartesianas, pôde determinar os tipos de correlações que se estabelecem na dinâmica valencial: correlações conversas, nas quais os termos predominantes de cada subdimensão operam paralelamente de forma juntiva, ou seja, se um dos termos aumenta, o outro aumenta e vice-versa (mais mais/menos menos), ou, por outro lado, por correlações inversas, nas quais os termos das subdimensões operam em cruzamento de forma disjuntiva, ou seja, se um dos termos aumenta, o outro diminui e vice-versa (menos mais/mais menos).

Outra premissa tensiva importante, também pertinente para a nossa análise específica, é que, por adotar o ponto de vista de que, de modo geral, toda produção de sentido é de natureza afetiva, a dimensão da intensidade exerce primazia sobre a dimensão da extensidade, ou seja, as direções dadas ou encontradas, em cada objeto específico, para 
as subdimensões de andamento e tonicidade regem as direções dadas para as subdimensões de temporalidade espacialidade.

Parece-nos importante apontar que, no decorrer do desenvolvimento do pensamento tensivo, outras projeções e outros modos de percepção estão relacionados a essas duas grandes dimensões que criam o espaço tensivo.

Gráfico 3 - Percepções das Dimensões Tensivas

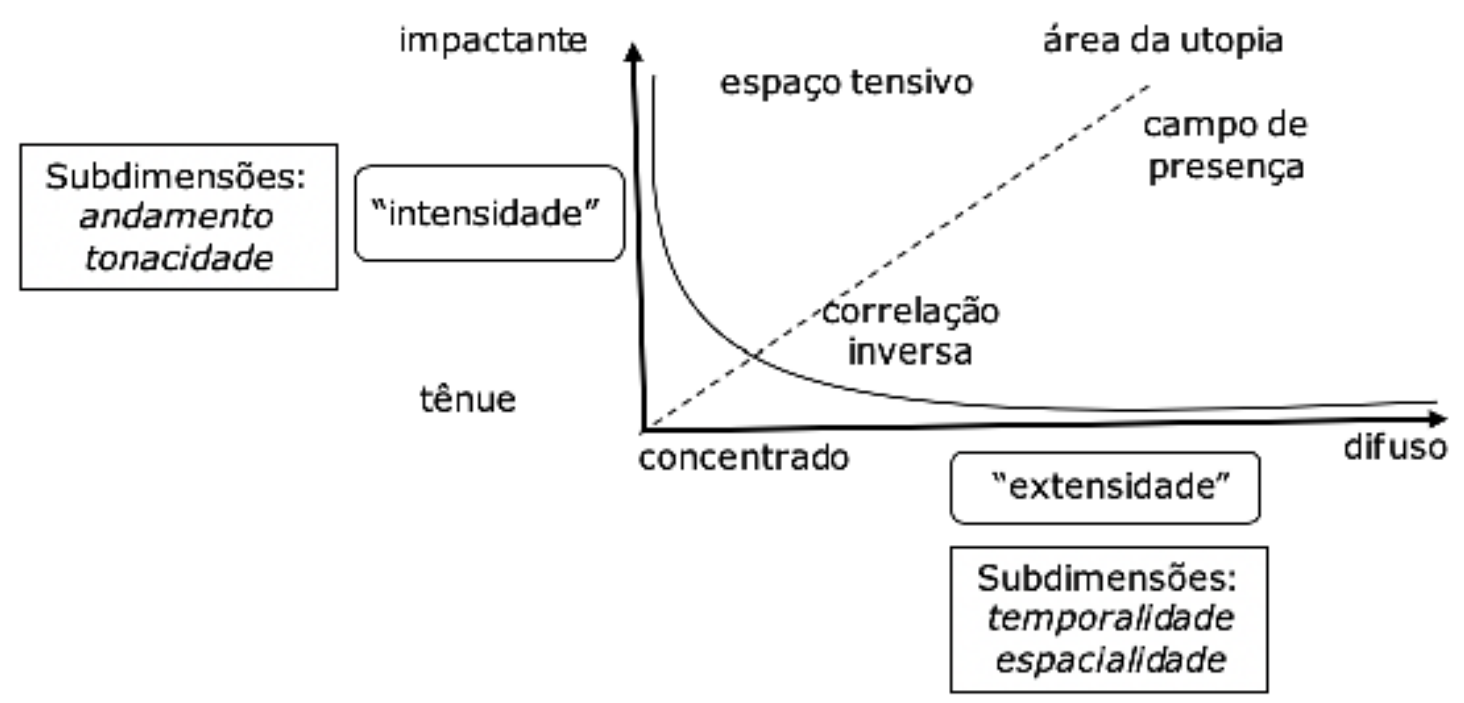

Fonte: Zilberberg (2011).

Ainda antes de voltar ao nosso objeto de análise, gostaríamos de trazer uma observação que Zilberberg faz sobre uma espécie de lei que se impõe, de maneira geral, ao discurso e que aponta para uma preferência das relações inversas. Mesmo que, logo em seguida a essa observação, ele a justifique com um exemplo da evolução dos discursos político e sociológico (monárquico vs. aristocrático), podemos inferir, pela observação da tipologia discursiva que está na raiz do sistema tensivo, que também sirva para os discursos poético-literários.

Como o fato semiótico é complexo, pensamos, à escuta dos discursos, que entre a intensidade e a extensidade se exerce uma "implacável" correlação inversa, uma "lei draconiana" que entrelaça, de um lado, o impactante e o concentrado e, de outro, o tênue e o difuso. (ZILBERBERG, 2011, p. 68)

Essa espécie de lei pragmática que o teórico destaca ao relacionar o impactante ao concentrado aponta, coerentemente, para o que ele vai denominar de lógica da gramática concessiva, no sentido de que, na extremidade do encontro dessas duas polaridades subdimensionais, estaria o advento do 'acontecimento', conceito fundamental na teoria tensiva. 
V. $10(2)$

1-16

maio-ago

2020

\section{Tensividade aplicada}

Tendo em vista esses aspectos da teoria, podemos tentar identificar quais são as grandezas que o arranjo das estrofes no poema Romance Sonámbulo faz vibrar no campo de presença e como as projeções em cada eixo, somente desse primeiro traço do plano da expressão, podem gerar sentidos que se coadunam ou se contrapõem aos sentidos gerados no plano do conteúdo. Pensamos em produzir, assim, uma análise tensiva mais ampla das produções de significados do poema.

Retomemos, então, a classificação dada para o arranjo das estrofes entre uniformes e variadas, atentando para o fato de que, nas estrofes chamadas uniformes, os procedimentos de separação (por conta do salto espacial entre linhas), de triagem (por conta da consequente comparação que se dá pelo paralelismo), de ordenação e de depuramento, que se dá pelo esforço de manter a característica marcante de cada estilo discursivo, corroboram entre si para a categoria ampla de /homogeneidade/. E, por outro lado, sob esse mesmo recorte analítico, nas chamadas estrofes variadas, os procedimentos de junção, de mistura, de variação da ordem e de entrelaçamento, que aqui se dão pelo esforço de diluir as características específicas de cada estilo, corroboram, como dito anteriormente, para a categoria de /heterogeneidade/. Mas quais são os sentidos que, ainda no plano da expressão, decorrem desses modos de estruturação?

Notamos que parece estarmos fazendo o caminho inverso, partindo das formas de arranjo da expressão para buscarmos o que elas projetam no eixo dos significados, contrariando a premissa tensiva, e da semiótica geral, de primazia do eixo da intensidade sobre o eixo da extensidade. No entanto, precisamos ter em vista que se trata ainda de um mesmo plano. Ou seja, por questão de método, buscamos primeiro a análise das produções de sentido do plano da expressão, demonstrado apenas um recorte, a saber: o do arranjo das estrofes, para, depois da análise de outros possíveis recortes desse mesmo plano, partirmos para a análise dos recortes do plano do conteúdo e, assim, relacionando as produções de sentido do conjunto de recortes dos dois planos, buscarmos - ou obtermos condições para tal - uma análise mais aprofundada da produção de sentido ampla do poema, o que já adiantamos que, por uma questão de propósito do trabalho, não será concluído neste único artigo.

Assim, partindo da contraposição entre as partes de estrofes do poema, identificamos as grandezas vibrantes no campo de presença. Seguindo, no entanto, o sentido de correlação inversa dado como 
preferencial pela teoria tensiva, tais projeções de sentido desse recorte da forma ficam evidentes.

A grandeza de /homogeneidade/, posta na análise da dimensão geral das valências tensivas intenso vs. extenso, contribui para o par tênue-difuso, enquanto a /heterogeneidade/, nessa mesma dimensão, contribui para o par impactante-concentrado.

Segundo as dimensões valenciais de intensidade e extensidade, observamos a descrição da correlação inversa que relaciona o aumento do impacto ao aumento da difusão:

Gráfico 4 - Dimensões Valenciais do Par /heterogeneidade/ vs. /homogeneidade/

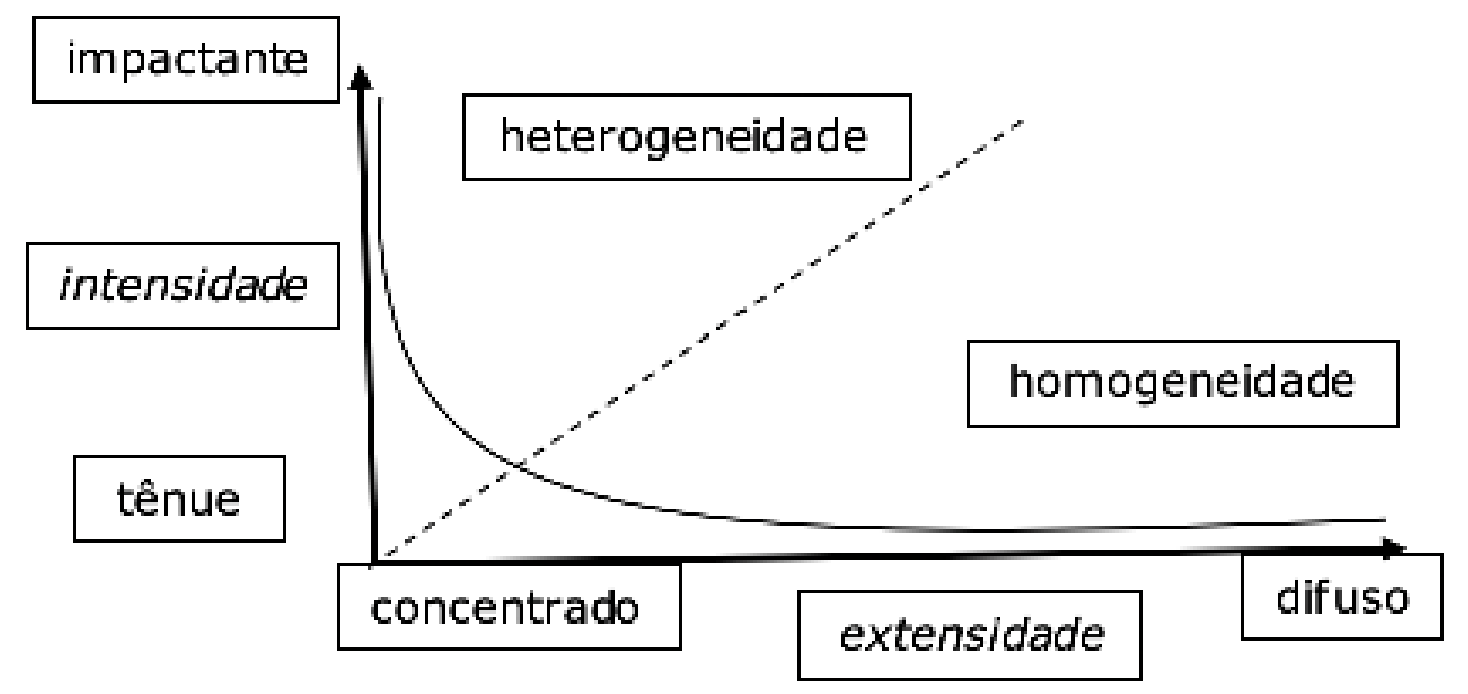

Fonte: Zilberberg (2011).

Nesse ponto, defrontamo-nos com uma contradição aparente: a tonicidade das estrofes heterogêneas não parece coerente com o procedimento de mistura, ao invés de triagem, que a elas está relacionado. No entanto, essa relação é explicável pela análise da espacialidade (gráfico 6), onde o fechamento se dá pela sua relação de conversão com o concentrado.

Assim, partindo para a projeção da grandeza de / homogeneidade/ nas subdimensões valenciais do extenso, tomando, a princípio, o forema de direção, obtemos, segundo a temporalidade, a apreensão e, segundo a espacialidade, o fechamento; e nas subdimensões do intenso, segundo a tonicidade, o átono e, segundo o andamento, a desaceleração. Consequentemente, encontramos, para a mesma projeção da grandeza de /heterogeneidade/ - ou seja, nas subdimensões valenciais, no extenso -, segundo a temporalidade, o foco e, segundo a 
V. $10(2)$

1-16 maio-ago 2020

espacialidade, a abertura; e, nas subdimensões do intenso, segundo a tonicidade, o tônico e, segundo o andamento, a aceleração.

Segundo as subdimensões de andamento e temporalidade, sob os foremas de direção, temos a descrição da correlação inversa que relaciona o aumento da aceleração ao aumento da apreensão:

Gráfico 5 - Análise das Subdimensões de Andamento e Temporalidade

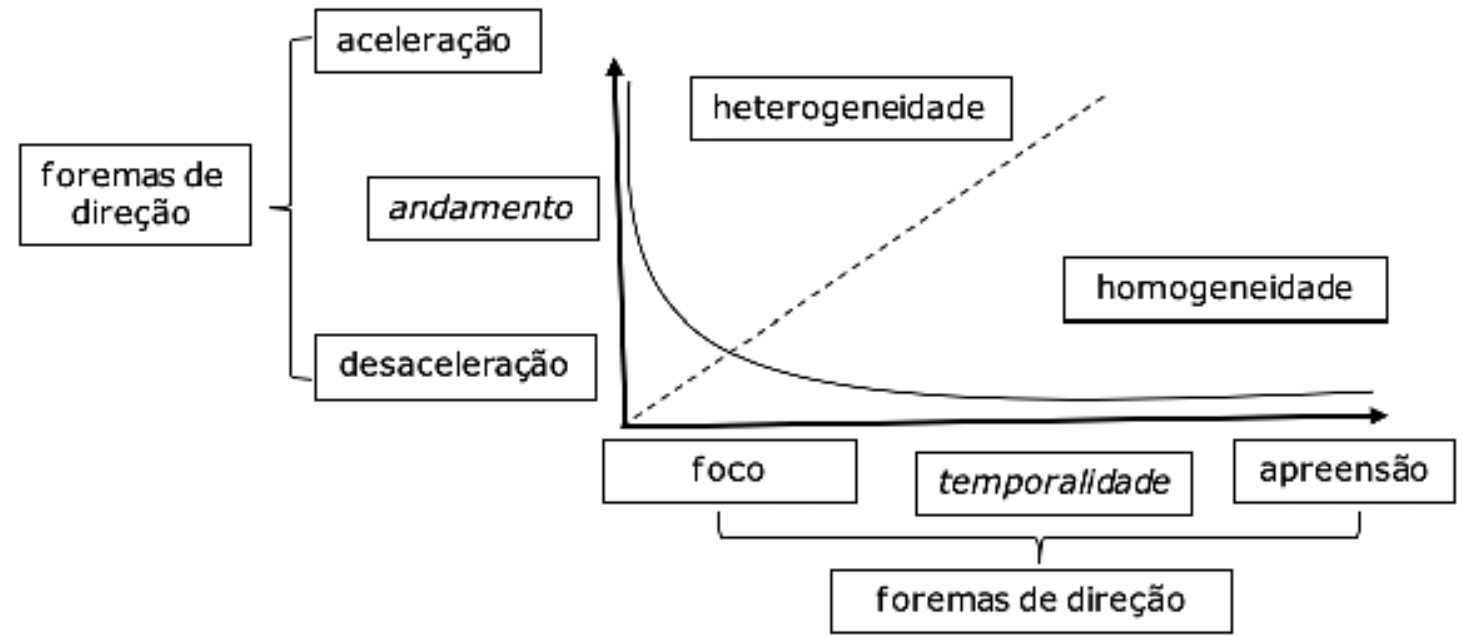

Fonte: Zilberberg (2011).

Segundo as subdimensões de tonicidade e espacialidade, sob os foremas de direção, temos a descrição da correlação inversa que relaciona o aumento da tonificação ao aumento do fechamento:

Gráfico 6 - Análise das Subdimensões de Tonicidade e Espacialidade

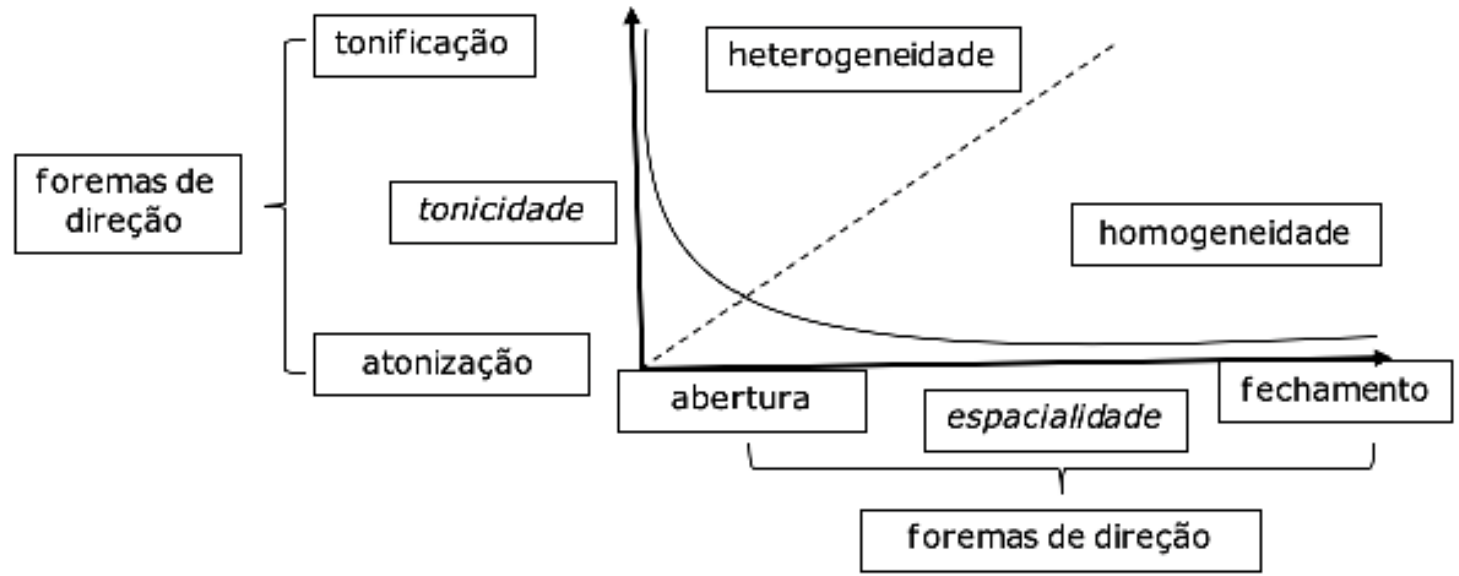

Fonte: Zilberberg (2011).

A consequência dessa análise é que, observando a movimentação das grandezas dentro do espaço tensivo, podemos estabelecer o modo como se cria a produção dos sentidos de um único 
recorte do plano da expressão e podemos, assim, comparar se o sentido desse recorte é coerente com os outros recortes desse mesmo plano.

Vale salientarmos que estão dispostos neste trabalho, segundo o modelo zilberbergiano, apenas as relações das valências subdimensionais dos valores vibrantes no campo de presença segundo o forema da direção, ou seja, o modelo descreve que estilos direcionais a /homogeneidade/ e a /heterogeneidade/ estabelecem na construção de sentido do objeto em análise. Uma descrição completa dos estilos tensivos de tais valores incluiria ainda a verificação, nos mesmos moldes, sob os foremas de posição e elã.

\section{Considerações finais}

Voltemos à pergunta que abre este artigo e possivelmente se insere no rol das questões fundamentais para a teoria semiótica de ponto de vista tensivo, assim como, para toda teoria científica emergente: para que serve?

Furtando-nos ao fato de tentarmos responder para que serve todo e qualquer avanço do pensamento científico, detemo-nos em uma pequena opinião sobre a tensividade dentro da semiótica, esta dentro das ciências da significação e da linguagem e estas, por sua vez, dentro das ciências humanas.

A primeira questão que nos vem à tona é a característica dinâmica desse tipo de análise. O modelo tensivo não lê o objetivo por partes, módulos ou sequências encadeadas, pois abandona a análise estática das partes.

Tomando o nosso objeto de análise como exemplo, vemos claramente que, por conta da sua natureza, o modelo tensivo desafia o analista a observar a relação entre as sequências identificáveis e o modo de transição entre os valores emergentes. Ou seja, no modelo zilberbergiano, o mais importante não éapenas demonstrar a constituição estrutural do objeto e tampouco quais os termos fundamentais que fazem vibrar o campo de presença. Ainda que essas sejam etapas importantes, a vocação do modelo é descrever a movimentação dinâmica desses valores e como ela reestrutura o próprio objeto de análise.

No poema de Lorca, identificar os valores que vibram o campo de presença na análise dos modos de estruturação dos estilos discursivos na sequência das estrofes faz com que o analista possa descrever a dinâmica dessa construção de sentido no decorrer da leitura do poema. $\mathrm{O}$ que nos interessa aqui não é apenas corroborar a validade de tais valores 
V. $10(2)$

1-16

maio-ago

2020

semânticos, mas elucidar como a passagem da /homogeneidade/ para a /heterogeneidade/ constrói no texto - no nível do plano de expressão visto até então - uma relação de intensificação crescente e como essa relação elabora sentidos que privilegiam o heterogêneo e suas projeções: o tônico, o aberto, o acelerado e o sujeito (na forma do foco).

Notemos, portanto, que a preocupação da análise tensiva, bem como de toda análise, não é apenas com as partes, mas sim com a relação entre elas. No Romance Sonámbulo, o que fica a ser demonstrado é se o privilégio da heterogeneidade há de se repetir em outros níveis do plano da expressão e, sobretudo, do plano do conteúdo. Caso tal hipótese, iniciada nesse breve artigo, seja comprovada, teremos um caminho a trilhar para buscar, na relação entre outros poemas e nas relações entre outras obras de outros estilos de Lorca, como o teatro por exemplo, como o discurso lorquiano constrói uma poética da abertura, da ruptura e da heterogeneidade.

\section{Referências}

ARISTÓTELES. Poética. Tradução Eudoro de Sousa. 2. ed. Lisboa: Imprensa Nacional - Casa da Moeda, 1990. Série Universitária. Clássicos de Filosofia.

FLOCH, J.-M. Semiótica plástica e linguagem publicitária. Tradução de José Luiz Fiorin. Significação: Revista de Cultura Audiovisual, n. 6, p. 29-50, 30 jan. 1987.

GARCÍA LORCA, F. Obra Poética Completa. (Ed. bilíngue). Trad. Willian Angel de Mello. 5. ed. São Paulo: Editora W Martins Fontes, 2012.

GARCÍA LORCA, F. Romancero Gitano. Madrid: Editora Austral. Col. Contemporánea, 2000.

GREIMAS, A. J. Semântica Estrutural: pesquisa de método. Tradução de Haquira Osakabe e Izidoro Blikstein. São Paulo: Editora Cultrix, 1973.

RIMBAUD, A. Obra Completa. Tradução de João Moita e Miguel Serras Pereira. Lisboa: Editora Relógio D'Agua, 2018.

ZILBERBERG, C. Elementos de Semiótica Tensiva. Trad. de Ivã Carlos Lopes, Luiz Tatit e Waldir Beividas. São Paulo: Ateliê Editorial, 2011.

ZILBERBERG, C. ¿Para que sirve la gramática tensiva? Revista Contratexto, Universidad de Lima, n. 17, p. 103-135, 2009.

ZILBERBERG, C. Razão e Poética do Sentido. Tradução de Ivã Carlos Lopez, Luiz Tatit e Valdir Beividas. São Paulo: EDUSP, 2006.

ZILBERBERG, C. Uma Tentativa de Leitura de Rimbaud: bonne pensée du matin. In: GREIMAS, A. J. (org.). Ensaios de Semiótica Poética. Tradução de Heloysa de Lima Dantas. São Paulo: Ed. Cultrix, 1975. 